\title{
MAIS UMA SALVA DE TIROS NA GUERRA PARADIGMÁTICA DA EDUCAÇÃO DO CAMPO
}

\section{Resumo}

\author{
Filipe Gervásio Pinto da Silva ${ }^{1}$
} Janssen Felipe da Silva ${ }^{2}$

Neste trabalho intencionamos construir uma reflexão sobre o panorama que se apresenta à Educação do Campo no Brasil, tendo como pano de fundo econômico e pedagógico o cenário nacional e internacional que circula a atual tensão paradigmática (ARROYO; CALDART; MOLINA, 2011) em torno desta modalidade educacional. Para tanto, a reflexão segue dois caminhos interdependentes. O primeiro caminho é contextual e trata do aprofundamento da hegemonia neoliberal na América latina (QUIJANO, 2005; ALVES, 2003) e do Agronegócio como interventor ativo na apropriação da Educação do Campo (JESUS \& JESUS, 2011). O segundo caminho diz respeito às reformas sociais e educacionais (as pretendidas e as que estão em debate) instituídas no contexto pós-golpe de 2016 e suas relações com o campo e com a Educação do Campo.

Palavras-chave: Educação do Campo; Agronegócio; Reformas Educacionais

\begin{abstract}
In this work we intend to construct a reflection about the panorama that presents itself to the Field Education in Brazil, having as economic and pedagogical background the national and international scenario that circulates the current paradigmatic tension (ARROYO; CALDART; MOLINA, 2011) in around this educational modality. For this, reflection follows two interdependent paths. The first path is contextual and deals with the deepening of neoliberal hegemony in Latin America (QUIJANO, 2005; ALVES, 2003) and Agribusiness as active intervenor in the appropriation of Field Education (JESUS \& JESUS, 2011). The second path concerns the social and educational reforms (both intended and debated) instituted in the post-coup context of 2016 and their relations with the field and with field education.
\end{abstract}

Keywords: Field Education; Agribusiness; Educational Reforms

\footnotetext{
${ }^{1}$ Professor da Universidade Federal de Campina Grande- Centro de Desenvolvimento Sustentável do Semiárido (UFCG/CDSA). Professor da Área de Fundamentos Sócio-históricos da Unidade Acadêmica de Educação do Campo. Pedagogo pela Universidade Federal de Pernambuco- Centro Acadêmico do Agreste (UFPE-CAA). Mestre em Educação Contemporânea pelo Programa de de Pós-Graduação em Educação Contemporânea (PPGEDUC). Membro do Grupo de Pesquisa Estudos Pós-Coloniais e Teoria da Complexidade na Educação. Endereço: Avenida Oscar Loureiro, no 51- Centro, Surubim/PE, Brasil. CEP: 55750-000. Tefefone: (81) 8914-3190. Email: filipe.gps@hotmail.com.

${ }^{2}$ Professor Associado II do Centro Acadêmico do Agreste (CAA) da UFPE. Professor Permanente do Programa de Pós-graduação em Educação do Centro de Educação (CE), Professor Permanente do Programa de Pós-graduação em Educação Contemporânea (CAA). Pedagogo pela Faculdade de Filosofia do Recife (1995), Mestre (2001) e Doutor (2007) em Educação pela Universidade Federal de Pernambuco (UFPE). Coordenador do Grupo de Pesquisa Estudos Pós-Coloniais e Teoria da Complexidade na Educação e do Instituto de Estudos da América Latina. Endereço: Rua 92, no 85-Jardim Paulista Baixo-Paulista/PE, Brasil. CEP. 53407-050. Telefone: (81) 9999-7781. Email: janssenfelipe@hotmail.com.
} 


\section{Introdução}

Este artigo realiza uma reflexão sobre as guerras paradigmáticas presentes na Educação do Campo, em um momento em que tantos camponeses morrem física e simbolicamente, seja porque se agudizam os conflitos fundiários no Brasil em favor do Agronegócio, seja porque as concepções de Educação do Campo passam, cada vez mais, a estarem em constante disputa. A já consagrada expressão "guerra das ciências" assume sentidos também no contexto da Educação do Campo, uma vez que as disputas sobre o sentido e a direção da produção de conhecimento, na verdade orbitam cenários sócio-pedagógicos em conflito, sobretudo no âmbito curricular. Ressaltamos, no entanto, que a guerra paradigmática aqui elucidada, ultrapassa o sentido gnosiológico de sua formulação, na medida em que a compreendemos para além do campo epistemológico, isto é, está situada nas trincheiras do debate sobre o sistema capitalista-colonial-patriarcal e da reestruturação neoliberal na América Latina e, principalmente, no Brasil.

A expressão dessa disputa é a apropriação do termo Educação do Campo e seus novos tensionamentos no contexto de rearticulação neoliberal. A fim de levar a cabo a proposta do texto, nos utilizamos do ensaio bibliográfico como forma de tornar inteligíveis os atuais Paradigmas da Educação do Campo.

Neste sentido, compreendemos que a importância de analisar os paradigmas que embasam e orientam a educação nos territórios campesinos se alarga para além dos limites da Educação Básica, seja porque esta está alicerçada em disputas econômicas, sociais, políticas e educacionais mais amplas; seja porque a Educação do Campo está relacionada não apenas às experiências oficiais/normatizas, como também àquelas experiências educativas que estão presentes nas experiências sociais campesinas (sejam de movimentos sociais, sindicatos, associações, comunidades, etc); seja porque é o próprio sistema sócio-metabólico do capital que produz determinações sobre os sistemas educacionais como um todo (MÉSZÁROS, 2011).

Ressaltamos que todo paradigma é constituído e constitui relações com ambiências econômicas, sociais, econômicas, políticas, epistemológicas na tentativa de oferecer uma explicação/proposta para a realidade. No contexto da Educação do Campo a guerra paradigmática se afirma como guerra pela chancela de formar, entendida a formação como dimensão pedagógica de um projeto de sociedade candidato à hegemonia. Historicamente a disputa paradigmática se deu entre o Paradigma da Educação Rural e o Paradigma da Educação do Campo.

O Paradigma da Educação Rural, que parte do ideário moderno/colonial/capitalista/patriarcal de reprodução do poder colonial, através de uma ideia de desenvolvimento que se confunde com crescimento capitalista (ARROYO; CALDART; MOLINA, 2011, SANTOS, 2010). Está articulado com as demandas da manutenção da burguesia agrária e da legitimação do processo de desenvolvimento industrial que enxerga o campo como um território a ser expurgado da cartografia econômica e pedagógica. Desta forma, o sujeito enunciador no Paradigma da Educação Rural é o modelo capitalista e euro-urbanocêntrico de educação e de sociedade efetivado pela colonialidade. Neste sentido, prioriza uma oferta de educação descontextualizada e assistencialista, que oportuniza seus integrantes a reprodução minimamente qualificada de sua mão-de-obra, em função da manutenção histórica dos estereótipos inferiorizantes dos povos do campo a serviço da sociedade capitalista. 
Em contraposição ao Paradigma da Educação Rural está o Paradigma da Educação do Campo que surgiu e foi desenvolvido no contexto das populações campesinas que reivindicaram, através de um heterogêneo conjunto de lutas, condições de oferta e continuidade da educação escolarizada nos territórios camponeses, que fosse pública, gratuita, laica e socialmente referenciada.

É preciso mencionar, ainda que sumariamente, que a Educação do Campo enquanto paradigma educacional autodeclarado como tal, fez do chamado Projeto Nacional Popular a o seu horizonte último de luta social, como pode ser visto nos principais documentos que integram o corpo documental da Educação do Campo nos anos de 1990 e 2000. Afasta-se, portanto de um horizonte de radicalização econômica e política pensada a partir de uma perspectiva assumidamente socialista. A opção pelas referências da pedagogia freireana, das pedagogias de contextualização e da terra contribuem por alimentar o atual debate pedagógico da Educação do Campo reivindicada como Paradigma da Educação do Campo, cuja ênfase é eminentemente epistemológica e não ontológica.

\section{2- Apropriação neoliberal da Educação do Campo}

Atualmente os povos historicamente afetados pelo poder do capital passaram a ocupar as pautas centrais da agenda do Neoliberalismo. Uma das grandes estratégias utilizadas pelo poder dominante consiste em integrar um universo de sujeitos e grupos sociais, na medida em que não se tornaram possíveis as condições de sua eliminação. Desta forma, a luta de determinados grupos sociais, não podendo simplesmente ser apagada, torna-se parte integrante das preocupações do Estado que age de forma apaziguadora e fetichista.

A apropriação é apaziguadora quando tende a instituir políticas ou ações pontuais que garantam a minimização dos conflitos, sejam eles trabalhistas, culturais, religiosos, dentre outros. Este apaziguamento, porém, não toca decisivamente nas estruturas da dominação, estendendo-se como uma ação de integração estatal.

A apropriação torna-se fetichista quando ultrapassa a barreira do apaziguamento e utiliza os próprios coletivos sociais, demandas e formas de mobilização subalternizadas para o esvaziamento de sentido original em função da incorporação dos princípios da produção e da racionalidade hegemônicas. Um exemplo paradigmático destas duas expressões é a Educação do Campo, inicialmente pensada de forma periférica no sistema nacional de educação e posteriormente utilizada como slogan do Agronegócio.

Esta relação paradoxal entre reconhecimento e apropriação atinge os povos campesinos e as lutas por educação nos territórios campesinos. Trata-se da tensão entre a incorporação fetichista ou crítica dos povos do campo nas políticas educacionais ${ }^{3}$. Esta tensão está presente no Neoliberalismo, que reestrutura o trato com as diferenças culturais e territoriais empregado pelo Liberalismo, todavia o faz de modo a não apenas assimilar e contemplar estas diferenças na esfera legal, senão a reestruturar os interesses capitalistas mediante a oficialização das diferenças e sua utilização tática aos interesses do Sistema Mundo Moderno Colonial (GROSFOGUEL, 2010).

\footnotetext{
${ }^{3}$ Claro está que dentro dos marcos do Estado capitalista, nenhuma reivindicação da classe trabalhadora pode ser incorporada de modo pleno e que irradie outras consequências críticas.
} 
Ressaltamos que a estratégia de focalização no discurso sobre as culturas/territórios tem como objetivo a interdição do debate sobre o discurso da desigualdade. Assim, por mais variadas que pareçam ser as formas de reconhecimento territorial/populacional o modus operandi produtivo permanece intocável com a estratégia de substituir o discurso da produção pelo discurso da cultura. Esta fetichização não opera significativamente nem mesmo no campo da própria cultura, dada a sua intervenção colonial e precária, nem no campo produtivo, dado o seu caráter mistificador e reestruturador dos arranjos produtivos dominantes.

Nos territórios campesinos vem ocorrendo a reestruturação das formas de produção capitalistas, nas quais as populações originárias são silenciadas em virtude dos interesses das elites agrárias brasileiras. A respeito deste contexto, Jesus e Jesus (2011, p. 150) nos oferecem uma análise do contexto de reestruturação capitalista quando afirmam que

nos últimos vinte anos, a reestruturação do capitalismo no campo vem ocorrendo com a implantação das grandes empresas internacionais para exploração do solo brasileiro e a prática da biopirataria, das transformações de biomas e de culturas e construção de hidrelétricas. Também os incentivos governamentais têm impulsionado o desenvolvimento do agronegócio; da implementação de alta tecnologia, para a produção da monocultura, como a soja e a cana-de-açúcar; da engenharia genética, que modifica as características dos alimentos por meio da transgenia; entre outros.

De toda esta conjuntura de reestruturação produtiva nos territórios campesinos brasileiros tem ganhado cada vez mais relevância o Agronegócio. Este modelo produtivo se confronta com as formas específicas de compreender a produtividade das comunidades camponesas. Desta forma, ainda que carregue os discursos de afirmação das diferenças campesinas o Agronegócio reitera a discriminação territorial com os povos do campo e suas formas específicas de administrá-los por fora da via da industrialização capitalista. Esta relação de imposição do Agronegócio traz uma concepção de Educação do Campo que expropria os sujeitos de aprender a cultivar as suas formas próprias de lidar com os territórios materiais e imateriais. Segundo Arroyo, Caldart e Molina (2011, p. $11)$

o debate da relação campo-cidade perpassa todas as dimensões da Educação do Campo. Por muito tempo a visão que prevaleceu na sociedade, continuamente majoritária em muitos setores, é a que considera o campo como lugar atrasado, do inferior, do arcaico. Nas últimas décadas consolidou-se um imaginário que projetou o espaço urbano como caminho natural único do desenvolvimento, do progresso, do sucesso econômico, tanto para indivíduos como para a sociedade. De certa maneira esta foi a visão-suporte para o processo de modernização da agricultura implementado no país.

Esta imposição das referências urbanas continua acontecendo na atualidade embora as diferentes populações campesinas sejam passíveis de serem reconhecidas e contempladas em uma política cuja estrutura já 
está muito bem definida. O paradigma a ser posto em prática tem como motor o Agronegócio, como demonstram inúmeras orientações contidas no Programa Nacional de Acesso ao Ensino Técnico e Emprego (Pronatec) e Programa Nacional de Educação do Campo (Pronacampo).

O Agronegócio, em função dos interesses do neoliberalismo, necessita de um modelo de trabalhador capaz de se adequar às exigências da monocultura assalariada de forma empreendedora, flexível e competente. Por esta razão tem influenciado a agenda política educacional afirmando a defesa dos ideários da Educação do Campo. Todavia esta defesa está ancorada na necessidade de se aproveitar das conquistas políticas dos Movimentos Sociais vinculados aos territórios campesinos numa relação de apropriação Segundo Vilhena Junior e Mourão (2012, p. 181),

a grande mídia aliada ao agronegócio tem interesse de legitimar que os camponeses e os indígenas são uma espécie em extinção. Por esta ótica, então, não seriam necessárias políticas públicas para essas populações, a não ser do tipo compensatórias, histórica e largamente utilizadas em função das próprias condições de precariedade e a partir de pressões sociais.

A ideia de que os povos campesinos estão em extinção não se constrói aleatoriamente, de modo que estão em extinção porque são inferiores, e a condição de inferioridade e extinção justifica a sua eliminação como resíduos da sociedade moderna/capitalista/colonial/patriarcal. Neste contexto revigora-se a Monocultura da Escala Dominante (SANTOS, 2010) urbana, segundo a qual os povos do campo são considerados locais. São considerados locais porque inferiores nas suas manifestações econômicas e educacionais. Uma vez que são inferiores, são impassíveis para oferecer uma alternativa globalmente válida que se contraponha ao modelo capitalista, e especificamente ao Agronegócio.

Assim, reestrutura-se a lógica da colonialidade do poder (QUIJANO, 2005) que expropria os habitantes dos territórios campesinos dos seus territórios econômicos, sociais, políticos, epistêmicos e pedagógicos em função de um modelo de produção que os coloca, juntamente à natureza, como elementos necessários de apropriação indiscriminada visando o lucro. O trabalho no campo, neste contexto, se desvincula da sua dimensão territorial para se tornar instrumento de negação das especificidades e projetos de vida dos territórios.

As atuais propostas de formação técnica lançam mão de discursos sobre a valorização e o sentimento de pertencimento ao campo quando menciona que não é preciso deixar o campo para obter uma formação de qualidade. Todavia esta formação privilegia modelos de educação que se desvinculam das bandeiras de lutas sociais levantadas pelos movimentos sociais vinculados aos territórios campesinos. Assim, se imediatamente não é preciso deixar o campo, o modelo de produção e de educação a ser adotado pressupõe o aprofundamento do vigor do Agronegócio, o que contraditoriamente e consequentemente tende a desterritorializar os sujeitos camponeses. Estes sujeitos terminam por encontrar formas de resistência na produção cooperada, solidária e na conservação imaterial dos seus territórios, de modo que para resistir à modernização conservadora "as populações do campo 


\section{dAEPE|}

vão alterando suas relações, porém a essência de sua condição se mantém, sua maneira de ser, seus símbolos, sua humanidade permanecem" (BELTRAME, CARDOSO E NAWROSKI, 2011, p. 107).

Outra das expressões contraditórias da institucionalização da Educação do Campo foi o PNLD-CAMPO. O referido programa ganha ainda mais relevo na medida em que consideramos os Livros Didáticos como suportes privilegiados para o desenvolvimento das práticas curriculares dos professores da Educação Básica, de modo que na maioria das instituições é o principal suporte de mediação pedagógica utilizado pelos professores (as).

Ressaltamos que é conhecida a articulação entre os grandes grupos editoriais privados e a produção de LD no Brasil. Desta forma, os interesses hegemônicos das elites responsáveis pela produção de LD atravessam a construção e distribuição dos LD, em consonância com as Avaliações Educacionais promovidas pelo Estado. De acordo com Silva (2012, p. 810),

os livros didáticos, impulsionados sobretudo pelo PNLD, são responsáveis por sessenta por cento de todo o faturamento da indústria livresca no Brasil. Os valores negociados entre o FNDE e as editoras que forneceram livros didáticos para o Ensino Fundamental em 2011, por exemplo, foi de R \$880.263.266,15 (Assessoria de Comunicação FNDE, 2010). O PNLD é, sem dúvida, um grande negócio para as editoras.

O PNLD-CAMPO é um exemplo emblemático de como no interior da estrutura de mercado editorial dos livros didáticos, as demandas campesinas foram enunciadas como passíveis de serem atendidas, via programa específico e diferenciado. Ocorreu, todavia, que em ambas as edições do programa (2013 e 2016) pouquíssimas coleções foram aprovadas e, ainda assim, muitos livros reproduziam a lógica capitalista, monocultural e colonialista de currículo.

No momento em que o Brasil passou pelo seu mais recente golpe de Estado, no ano de 2016, as próprias políticas neoliberais começaram também a colapsar. Não por uma alternativa paradigmática emancipatória, senão pelo esvaziamento das próprias políticas de ajuste já precárias (O PNLD-CAMPO foi extinto). A radicalização de conflitos políticos (sobretudo no campo), o enxugamento em investimentos em gastos primários como a educação e o momento de centralização e autoritarismo social e pedagógico evidenciaram não apenas um atendimento precário da Educação do Campo, senão o abandono e silenciamento das demandas desta modalidade educacional no Brasil.

\section{3 - Reestruturação neoliberal e neoconservadora como projetos de formação no campo}

O conjunto de transformações que estão a ocorrer neste momento no cenário nacional e internacional demarca a reestruturação do sistema sócio metabólico do capital internacional (MEZAROS, 2011), através da hegemonia do capital financeiro (ALVES, 2003) e não mais do Capitalismo Industrial. Trata-se da hegemonia do

Capital Fictício (HARVEY, 2016), obtido pela acumulação de capital relativa ao trabalho improdutivo e 
especulativo, que tem como sujeitos principais, os fundos de pensão, bancos, sistemas de crédito e bolsas financeiras. Desta forma, o trabalho social e a força de trabalho humana deixa de ser a célula principal de geração de lucros, deixando de ser a força de produção de valor social (e consequentemente de mais-valor para a classe capitalista). Esta rearticulação neoliberal na América latina tem se caracterizado, sobretudo pelas respostas oferecidas à crise econômica. Estas respostas são materializadas através das reformas sociais e educacionais.

Do ponto de vista nacional, a ofensiva das políticas neoliberais e neoconservadoras, aprofundadas no contexto pós-golpe 2016, tem materializado um conjunto de reformas. Na escala societal, as três principais reformas em pauta são:

1) EC 95, emenda à constituição $\mathrm{n}^{\circ}$ 55, de 2016 - PEC do teto dos gastos públicos, que altera o Ato das Disposições Constitucionais Transitórias, para instituir o Novo Regime Fiscal, e dá outras providências;

2) Reforma Trabalhista, Lei no 13.467, de 13 de julho de 2017, que Altera a Consolidação das Leis do Trabalho (CLT), aprovada pelo Decreto-Lei no 5.452, de 10 de maio de 1943, e as Leis nos 6.019, de 3 de janeiro de 1974, 8.036, de 11 de maio de 1990, e 8.212, de 24 de julho de 1991, a fim de adequar a legislação às novas relações de trabalho;

3) Reforma da Previdência Social (pretendida pelo governo). Projeto de Emenda à Constituição 287/2016, que altera os arts. 37, 40, 109, 149, 167, 195, 201 e 203 da Constituição, para dispor sobre a seguridade social, estabelece regras de transição e dá outras providências.

A primeira reforma assume um caráter matricial, uma vez que determina o congelamento dos investimentos públicos durante vinte anos, congelamento este que pressupõe o estrangulamento dos fundos públicos para a manutenção da taxa de lucro da elite rentista brasileira. O tesouro nacional brasileiro é hoje, em sua maioria, destinado a juros e amortizações da dívida pública. Estes interesses não são suprimidos pela EC 95, que não desautoriza a relação retroalimetadora do governo com os fundos privados.

Não existe em nenhuma nação, nenhum paralelo a esta medida adotada pelo governo brasileiro, de tal modo que ela inviabiliza não apenas o orçamento da garantia dos direitos primários fundamentais, senão o próprio funcionamento das universidades e escolas públicas brasileiras. Também o próprio PNE estará comprometido não apenas em suas metas de financiamento, senão na execução de todas as iniciativas previstas para os próximos anos.

A Reforma Trabalhista, opera no sentido de flexibilização da Consolidação das Leis do Trabalho (CLT), e tem repercussões diretas para o hiato entre o aprofundamento da jornada de trabalho, pela espoliação dos trabalhadores e as condições de estabilidade, condições de trabalho e remuneração.

Como uma tendência do modelo de gestão Toyotista, a desregulamentação da economia, a perda de garantias trabalhistas fundamentais e a oficialização de que "o negociado junto a patrões e empregados vigora sobre o legislado" são marcas fundamentais da atual reforma. 
Nesse sentido, sofrem profundas alterações tanto as funções melhor remuneradas, quanto aquelas que já se encontram precarizadas, haja visto que a medida promove uma maior rotatividade no mercado, demissões, aumento da jornada de trabalho e trabalhos intermitentes. Aprofunda-se, particularmente nesse âmbito o fascismo contratual, que tende a produzir um assédio cada vez maior nos trabalhadores em relação à espoliação.

São expressões da atual reforma a permissão para gestantes/lactantes trabalharem em lugares insalubres, o pagamento aos trabalhadores com alimentação e moradia no campo, além da total ausência de estabilidade no emprego. Como é possível inferir, os territórios campesinos tenderão a sofrer mais com as mudanças ocorridas na Reforma Trabalhista, que altera mais 100 pontos da CLT anterior.

A Reforma Previdenciária está no conjunto de reformas pretendidas e não aprovadas, mas fortemente pautadas cotidianamente pela grande mídia televisiva, de rádio, impressa e digital. A pretensão governamental é a de que esta reforma funcione aumentando as condições de contribuição e tempo corrido até o momento da aposentadoria dos cidadãos brasileiros.

As mudanças pretendidas desconsideram totalmente as expectativas de vida no Brasil e as diferenças sócio-territoriais da relação com o trabalho. Também o valor integral da aposentadoria deixa de ser um direito, para estar condicionado ao tempo de contribuição e ao trabalho social. É preciso mencionar que a Previdência Social uma das fontes de desvinculação de receitas da União para o pagamento de juros e amortizações da dívida pública negociada com o capital financeiro, que na crise sistêmica hoje vivenciada necessita manter suas taxas de lucros.

A reforma previdenciária afetaria diretamente muitas localidades campesinas que tem suas fontes de receita em aposentadorias e também em atividades relacionadas ao setor primário e de comércio de pequeno porte. Isto ocorre porque as principais fontes de renda que movimentam as economias destes locais estão baseadas em aposentadorias e receitas de programas de proteção social.

A propósito do campo brasileiro, nas últimas décadas vem crescendo a influência dos setores produtivos articulados à agricultura industrial/patronal. Esse crescimento vem sendo municiado pelos diferentes governos que assumiram a presidência da República através do financiamento de insumos, fertilizantes, ampliação da capacidade de produção agrária, dentre outros.

Paralela e consequentemente, diminui o espaço da agricultura familiar e com ela, a capacidade de produção orgânica, agroecológica e que possui capacidade de circulação de integrar a parcela maior da alimentação dos brasileiros.

A gestão da água é igualmente importante no cenário pós-golpe, uma vez que a gestão da água, mais do que nunca, tende a intensificar as investidas no atual arranjo produto hegemônico nos territórios campesinos.

No contexto pós-golpe, voltaram à tona as discussões sobre a privatização dos principais mananciais de água doce do Brasil, como o Aquífero Guarani. Como exemplo nacional de desmonte de serviços básicos, o caso da gestão neoliberal das águas do estado de São Paulo.

A reboque do modelo de agricultura industrial, capitaneada pelo Agronegócio e da gestão das águas atrelada ao modelo de produção agroexportadora e privatista, várias medidas vêm sendo discutidas, como a liberação de armas no campo no momento em que os índices de homicídios no campo bateram recordes e mesmo 
aprovadas; como o Projeto de Lei 6.299/2002, que permite mudanças na fiscalização e no controle dos agrotóxicos no Brasil.

A medida possibilita a entrada de agrotóxicos que são proibidos em todas as partes do mundo, com exceção do Brasil e vem acompanhada ainda da proibição da venda de alimentos orgânicos em supermercados.

No campo das movimentações sociais em torno do cenário político instituído, ocorre hoje no Brasil a criminalização das resistências protagonizadas pelos movimentos sociais e por qualquer grupo ou corpo-político que tenha interesses análogos às causas sociais populares. Esta repressão se deve a três fatores, sendo eles o braço armado do Estado brasileiro, que, ainda que não assuma o protagonismo do golpe instituído, garante-lhe retaguarda e a já conhecida segurança nacional; o neoconservadorismo crescente que produz uma vigilância sobre as reivindicações sociais pela violência física e simbólica e; como aparato legal, a Lei Antiterrorismo- Lei $\mathrm{n}^{\circ}$ 13.260, de 16 de março de 2016, que criminaliza a ação de movimentos sociais que se rebelem frontalmente com o governo.

Esta ambiência corre de par com a subalternização das diferenças culturais e sócio-territoriais presentes nos territórios campesinos do Brasil: pela negação do acesso a políticas públicas, como desdobramento da política de austeridade que afeta dimensões significativas da vida no campo, como a reforma agrária e a política de assentamentos; como também pela inferiorização produzida através do fascismo social. Estas variáveis de dominação no campo culminam com as preocupações educacionais que, do ponto de vista nacional têm significado a erosão quase completa da política federal de Educação do Campo.

Estas formas de experienciar os conflitos e as resistências nos territórios campesinos ganham uma nova complexidade com a implementação das reformas educacionais no Brasil. Ainda no campo educativo, o golpe de 2016 aprofunda um momento pedagógico de exceção com o a aprofundamento das políticas de corte neoliberal para a Educação, que sinalizam para processos de decisão curricular e pedagógica cada vez mais centralizados e sem participação da sociedade civil (apenas da sociedade civil íntima a privatista, como já mencionado). As reformas educacionais possuem amplitude nacional mas afetam os territórios campesinos de modo distinto, dadas as especificidades da vida nos diferentes territórios campesinos. Na escala educacional, as principais reformas em curso são:

\section{1) A Base Nacional Comum Curricular- BNCC;}

2) A Reforma do Ensino Médio, inicialmente anunciada como Medida Provisória $n^{\circ}$ 746/2016, e posteriormente aprovada enquanto Lei de Conversão 34/2016 e;

3) O Projeto Escola Sem Partido (pretendida no governo Temer), Projeto de Lei do Senado $n^{\circ} 193$, de 2016, que inclui entre as diretrizes e bases da educação nacional, de que trata a Lei no 9.394, de 20 de dezembro de 1996, o "Programa Escola sem Partido". 
Ressaltamos que há uma interdependência dessas reformas em relação às reformas operadas do ponto de vista social. O primeiro projeto, que se constitui como matricial do ponto de vista curricular, uma vez que as outras reformas se justificam e tomam como referência direta as demandas anunciadas pela BNCC. Compreendemos que a BNCC aglutina em torno de si a pretensão de reunir um conjunto de disposições curriculares que sirvam de norma geral, cuja obediência deve ser mantida por todas as realidades nacionais e por qualquer futura alteração substancial nas políticas educacionais e nas políticas curriculares. Neste sentido, constitui-se como a célula matricial de transformação curricular da Educação Básica e, com ela, também da Educação do Campo.

A consolidação da BNCC tem sido possível através do protagonismo exercido pelos reformadores empresariais no plano das concepções, dos objetivos e da estrutura adotada pelo documento que normatizará os currículos do ponto de vista nacional (ALVES, 2014). Trata-se da afirmação do Paradigma de Colaboração Integrativo (MACEDO, 2014), pactuando a gestão da educação pública com empresas privadas. Estas empresas que exercem protagonismo na formulação e divulgação da BNCC estão dispostas em três agrupamentos principais, sendo eles: a) Itaú (UniBanco); Bradesco; Santander, Gerdau, Natura e Wolkswagen; b) "Todos Pela Educação": Fundação Lemam, Gerdau, Camargo Correia e c) CENPEC- Itaú, Wolskwagen e Telefônica (MACEDO, 2014).

A BNCC se apresenta, de forma elementar, como uma estrutura curricular que possui um núcleo geral ou universal e um núcleo específico ou diferenciado, que se constitui das especificidades de cada região, sistema de ensino e formas de materialização da educação escolarizada. A eleição do Universal e do Global, com nos lembra Santos (2010) foi historicamente marcada pela Monocultura da Escala Dominante, na qual uma entidade geohistórica, econômica ou epistêmica designa entidades rivais como locais. Neste sentido, a BNCC passa ao longe de dois questionamentos fundantes: o que cabe no universal e em que perspectiva/abordagem ele será tratado e quem elegeu o próprio universal como universal?

Desta forma, torna-se importante compreender como "agricultores familiares, extrativistas, pescadores artesanais, ribeirinhos, assentados, acampados da reforma agrária, quilombolas, caiçaras, indígenas" (BRASIL, 2009 , p. 1) e "outros que produzam suas condições materiais de existência a partir do trabalho no meio rural" (BRASIL, 2010, p.1) se exercem do ponto de vista curricular na BNCC.

A Reforma do Ensino Médio pressupõe a flexibilização dos conteúdos, diminuição das 13 disciplinas tradicionais, encurtamento do tempo de oferta geral básica, que era de 3 anos e que passa a ser de $60 \%$ da jornada. Os 40\% da jornada escolar serão distribuídos na vivência de um dos 5 itinerários formativos (Formação Técnica e Profissional; Linguagens e suas Tecnologias; Matemática e Suas Tecnologias; Ciências da Natureza e suas Tecnologias e Ciências Humanas e Sociais Aplicadas). Esta reforma dá maior peso do Ensino Técnico e incentivo à ampliação da jornada em tempo integral.

No território do campo, a restrição da oferta do Ensino Médio agravará um quadro que já é de precarização da oferta, uma vez que o Ensino Médio ainda é um direito não consolidado na maioria dos territórios camponeses do Brasil. O Projeto Escola Sem Partido incorpora mais detidamente os aspectos do neoconservadorismo que demarca o conjunto de reformas educacionais, na medida em que parte da premissa de supressão das interfaces políticas e sociais de qualquer conteúdo escolar, da vigilância e da quebra da autonomia do trabalho docente e da instauração de uma pretensa neutralidade curricular e pedagógica. 


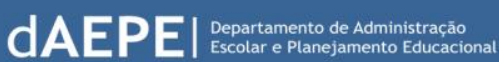

As repercussões do Escola Sem Partido nos territórios campesinos estão diretamente associadas à criminalização do pensamento crítico, seja em sua versão histórica, sociológica ou filosófica que se vincule aos movimentos sociais do campo e às pedagogias do campo. Desta forma, todas as iniciativas pedagógicas, curriculares e de organização do trabalho pedagógico que estejam articuladas aos territórios campesinos, serão criminalizadas por realizarem discussões político-pedagógicas.O currículo da Educação do Campo passa então a ser sitiado por agentes e lógicas que negam os próprios sujeitos do lugar como produtores de vida, epistemologias e formas de organização escolar e pedagógica específicas e diferenciadas. Assim, consolida-se a monocultura curricular, cuja materialização se dá não pela exclusividade de uma única cultura (euro-urbanocentrada, branca, cristã, heterossexual e masculina) no currículo, senão pela predominância da hegemonia cultural sobre as demais culturas, de modo a subalterniza-las e, na medida do possível, silencia-las por completo.

\section{Referências}

ALVES, Giovani Antônio Pinto. Toyotismo, Novas Qualificações e Empregabilidade: Mundialização do Capital e a Educação dos Trabalhadores no Século XXI. Educação (UFAL), Macéio, v. 10, n.16, p. 61-76, 2003

\section{ALVES, Nilda. Sobre a possibilidade e a necessidade curricular de uma Base Nacional}

Comum. Revista e-Curriculum, São Paulo, v. 12, n. 03 p. 1464 - 1479 out./dez. 2014

ARROYO, M. G.; CALDART, R. S.; MOLINA, M. C. Por uma educação do campo. 5. ed. Petrópolis, RJ: Vozes, 2011.

BELTRAME, S. A. B.; CARDOSO, T. M.; NAWROSKI, A. Educação do campo e práticas pedagógicas. In: MURAMIM, A. et al. (Org.). Educação do campo: políticas públicas, territorialidades e práticas pedagógicas. Florianópolis: INSULTAR, 2011.p. 101-122.

BRASIL. Resolução CEE/PE $\mathbf{N}^{\circ} \mathbf{2}$ de 31 de Março 2009. (Institui diretrizes, normas e princípios para a Educação Básica e suas Modalidades de Ensino nas Escolas do Campo que integram o Sistema de Educação do Estado de Pernambuco).

GROSFOGUEL, R. Para descolonizar os estudos de economia política e os estudos pós-coloniais: transmodernidade, pensamento de fronteira e colonialidade global. In: SANTOS, B. S.; MENESES, M. P. (Orgs.). Epistemologias do Sul. São Paulo: Cortez, 2010. p. 455-491.

HARVEY, David. 17 contradições e o fim do capitalismo. 1. ed. São Paulo: Boitempo, 2016.

JESUS, Sônia Meire Santos Azevedo de; JESUS, Carlos Alberto. Currículo por área de conhecimento na formação de professores para escolas do campo da UFS. In: MOLINA, Mônica Castagna.; SÁ, Laís Mourão. (Org.). Licenciaturas em educação do campo: registros e reflexões a partir das experiências - piloto (UFMG: UnB: UFBA e UFS). Belo Horizonte: Autêntica, 2011. p. 149-164.

MACEDO, Elizabeth. Base Nacional Curricular Comum: novas formas de sociabilidade produzindo sentidos para educação. Revista e-Curriculum, São Paulo, v. 12, n. 03 p.1530 - 1555 out./dez. 2014

MÉZAROS, Istiván. Para além do capital: rumo a uma teoria da transição. 1 ed. São Paulo: Boitempo, 2011.

QUIJANO, Aníbal. Colonialidade do poder. In: LANDER, Egdardo. (Org.). A colonialidade do saber: eurocentrismo e ciências sociais. Perspectivas latino-americanas. Buenos Aires: CLACSO, 2005. 


\section{REVISTA DE ADMINISTRAÇÃO EDUCACIONAL}

SANTOS, Boaventura de Sousa. A gramática do tempo para uma nova cultura política. 3. ed. São Paulo: Cortez, 2010.

SILVA, M. A. A Fetichização do Livro Didático no Brasil. Educação \& Realidade, Porto Alegre, v. 37, n. 3, p. 803-821, set./dez. 2012.

VILHENA JÚNIOR, Waldemar Moura; MOURÃO, Arlinda Rangel Botelho. Políticas públicas e os movimentos sociais por uma educação do campo. In: GHEDIN, Evandro. (Org.). Educação do campo: epistemologia e práticas. São Paulo: Cortez, 2012. p. 169-194. 